\title{
Vorwort zur Deutschen Ausgabe.
}

Die Vorlesungen über den Ursprung und die Entwickelung der Religion, welche ich auf Wunsch des Verwaltungs-Raths des Hibbert'schen Vermächtnisses im April, Mai und Juni des Jahres 1878 im Chapter-House von Westminster-Abbey gehalten habe, schienen keines Vorworts zu bedürfen. Was sie wollen, sagen sie in der ersten Zeile. $\mathrm{Ob}$ sie das, was sie wollen, wirklich geleistẹt haben, darüber steht Andern, nicht mir, ein Urtheil zu. Aus den zahlreichen Beurtheilungen jedoch, welche dieselben, theils im Original, theils in der Französischen Uebersetzung von M. James Darmesteter, erhalten haben, scheint mir hervorzugehen, dass dieselben im Ganzen ihren Zweck erfüllt und die Aufmerksamkeit der philosophisch gebildeten Leser auf den Brennpunct alles Denkens der Gegenwart hingelenkt haben, Wie gelangen wir zum Uebersinnlichen, oder, wie man es sonst mit mehr oder weniger scharf schattirten Namen nennen mag, Wie gelangen wir zum Transscendentalen, zum Unendlichen, zum Göttlichen?

Meine Freunde auf der rechten Seite, namentlich in Indien (Theistic Quarterly Review, October, 1879), meinen, dass ich dem Materialismus und Empirismus zu grosse Zugeständnisse gemacht habe, indem ich den ersten An- 
stoss zur Religion im Sinnlichen, im Druck des Unendlichen im Endlichen, nachzuweisen suche.

Meine Freunde auf der linken Seite sind noch mehr ungehalten, weil ich ganz vor-Kantisch dem von uns nur postulirten Unendlichen Realität zuerkannt, das jenseits des menschlichen Gesichtskreises liegende Unerkannte oder Unerkennbare zum Unendlichen und Göttlichen erhoben, und so dem Transscendentalismus Thor und Thür geöffnet habe.

Meine Antwort an beide Parteien ist dieselbe. Läugnet das Sinnliche oder läugnet das Uebersinnliche, wenn Ihr könnt. Wenn Ihr aber nicht könnt, wenn das eine so handgreiflich ist wie das andere (siehe Seite 40-53), so zeigt mir eine andere Brücke, die vom Siunlichen zum Uebersinnlichen führt.

Meine Arbeit war hauptsächlich historisch, genetisch, oder, wie man es jetzt auch wohl nennt, evolutionär. Wenn wir wissen wollen, wie der Mensch dazu kommt, eine Religion zu haben, oder überhaupt über das sinnlich Wahrnehmbare und verständlich Begreifbare hinauszugehen, so müssen wir eben sehen, wie er dazu gekommen ist, d. h. wir müssen die historische Entwickelung des religiösen Bewusstseins zu erkennen suchen. Dies können wir nicht im Grossen und Ganzen mit der ganzen Menschheit en bloc thun, sondern nur indem wir jeden einzelnen Strom der religiösen Denk- und Sprechweise von ihrer Quelle bis zu ihrer Mündung verfolgen. Dies ist es, was ich mit der alten indischen Religion zu thun versucht habe, indem ich den Kern aus der Schale, den lebendigen Keim aus dem Kern herauszuschälen und die Entwickelung der Idee klar hinzustellen versuchte, welche den Indier von der tiefsten bis zu der höchsten Stufe 
religiösen Denkens geführt hat. Anfang, Mitte und Ende liegen hier klar vor Augen. Ein Zurückgehen über den tiefsten Standpunkt der Vedischen Religion ist wohl möglich, ist aber für unsere Zwecke unnöthig, weil derselbe, so wie er ist, wenn auch nicht voraussetzungslos, doch vollkommen begreiflich ist. Ein Weitergehen über den in den Upanischaden erreichten Standpunkt ist nicht möglich. Selbst der Buddhismus, der philosophisch von den Upanischaden ausgeht, kommt nicht über den Vedânta, über das sein Höchstes Selbst erkennende Selbst hinaus. Er geht in der Entwickelung der religiösen Idee nur rückwärts, entweder in den schon überwundenen Nihilismus, oder in die Verehrung mythologischer Götter, eines Avalokitesvara, Amitâbha oder Âdi-buddha verfallend. Die religiöse Idee, auf deren Entwickelung ich mich beschränkt habe, fängt im Veda an und findet im Veda ihren Abschluss.

Weil nun aber die religiöse Entwickelung sich im alten Inllien so genau verfolgen, so vollständig auf jeder Stufe begreifen lässt, so folgt durchaus nicht, dass sie die einzig mögliche oder die einzig richtige sei. Sie ist eben nur eine von vielen und hat als solche ilhre historische Berechtigung. Es ist das Ziel der Vergleichenden Theologie, wie sie jetzt durch Männer wie Pfleiderer, Happelt, Reville, Tiele vertreten wird, alle naturwüchsigen Religionen in ihrem Entstehen und Vergehen zu begreifen, um daun im Vielen das Eine, im Wechselnden das Bleibende, im Falschen das Wahre zu erkennen. Während man sonst die Uebereinstinmungen zwischen den sogenannten falschen Religionen und der wahren Religion dazu benutzte, um letztere herabzusetzen, stützt sich die Vergleichende Religionswissenschaft gerade auf diese Uebereinstimmungen, 
um Religion, als solche, als etwas Unvermeidliches hinzustellen, d. h. als ebenso unvermeidlich wie, um mit Kant zu reden, die Formen der sinnlichen Anschauung, Raum und Zeit, und die Kategorien des Verstandes. Wer damit nicht zufrieden ist, der sehe sich nach anderen Bundesgenossen um. So weit ich das geistige Schlachtfeld der Gegenwart kenne, glaube ich nicht, dass Atheismus und Nihilismus mit dem kleinen Katechismus in die Flucht geschlagen werden können.

Die deutsche Bearbeitung meiner Vorlesungen rührt theils von mir selbst her, theils von Herrn Dr. Oscar Meyer, Custos an der Kais. Universitäts- und Landesbibliothek in Strassburg. Die vierte und fünfte Vorlesung sind von ihm übersetzt, und sind, wie mir scheint, die gelungensten im ganzen Werke. Ausserdem hat sich dersclbe der mühevollen Arbeit unterzogen meine Uebersetzung mit dem Original zu vergleichen, Fehlendes nachzutragen und die Citate zu ordnen, wofür ich ihm hiermit meinen besten Dank abstatte.

$$
\text { Oxf ord, 6. Februar } 1880 \text {. }
$$

\section{F. Max Müller.}


